Check for updates

Cite this: RSC Adv., 2019, 9, 30917

\title{
Rhodamine B derivative-modified up-conversion nanoparticle probes based on fluorescence resonance energy transfer (FRET) for the solid- based detection of copper ions $\dagger$
}

\author{
Xiaoyan Liu, (DD ac Nan Ding, ${ }^{\mathrm{b}}$ Jun Wang, ${ }^{\mathrm{c}}$ Honglan Chen, ${ }^{\mathrm{c}}$ Xinwei Chen, ${ }^{\mathrm{c}}$ \\ Zhidong Wang ${ }^{a}$ and Xincun Peng*a
}

\begin{abstract}
Herein, a novel solid-based up-conversion fluorescence resonance energy transfer (FRET) sensor was developed using rhodamine $B$ hydrazide, which provided a selective fluorescence response and suitable affinity towards $\mathrm{Cu}^{2+}$ ions over other biologically relevant metal ions because the $\mathrm{Cu}^{2+}$ ion could promote the hydrolysis of $\alpha$-amino acid esters of rhodamine B hydrazide and yield the $\mathrm{Cu} \cdot \boldsymbol{\alpha}$-amino acid chelate. This solid-based detection system is more convenient for the detection of $\mathrm{Cu}^{2+}$ based on color change and emission spectra instead of the complicated and tedious measurements than other upconversion sensors and up-conversion luminescent nanoparticles used as an excitation source; moreover, the proposed system shows high selectivity, minimum photo-damage to living organisms, and high chemical stability.
\end{abstract}

Received 17th July 2019

Accepted 6th September 2019

DOI: 10.1039/c9ra05504e

rsc.li/rsc-advances

A number of studies have been conducted on $\mathrm{Cu}^{2+}$ detec-

\section{Introduction}

Copper ion, as the third most abundant essential transition metal ion, plays a critical role in human health and environmental science, ranging from the diagnosis of life-threatening diseases to the analysis of environmental pollutants. ${ }^{1-3}$ However, when the $\mathrm{Cu}^{2+}$ ion is present at significantly high or low concentrations, it leads to serious human diseases; ${ }^{4,5}$ moreover, $\mathrm{Cu}^{2+}$ is non-degradable and can accumulate in the environment; hence, $\mathrm{Cu}^{2+}$ ion in excessive amounts will result in environmental pollution throughout the world due to its widespread use in industries, agriculture, household utensils, and water pipes. Therefore, the development of fast, convenient and reliable methods for the qualitative and quantitative detection of trace amounts of $\mathrm{Cu}^{2+}$ ions is of significant importance considering the biological and environmental implications of excess $\mathrm{Cu}^{2+}$ ions.

\footnotetext{
${ }^{a}$ Engineering Research Center of Nuclear Technology Application, Ministry of Education, Engineering Research Center of New Energy Technology and Equipment of Jiangxi Province, East China Institute of Technology, 418 Guanglan Avenue, Nanchang 330013, China. E-mail: xcpeng@ecit.cn

${ }^{b}$ State Key Laboratory on Integrated Optoelectronics, College of Electronic Science and Engineering, Jilin University, 2699 Qianjin Street, Changchun 130012, China

'Institute for Electric Light Sources, School of Information Science and Technology, Engineering Research Center of Advanced Lighting Technology, Academy of Engineering and Technology, Fudan University, Shanghai 200433, China

$\dagger$ Electronic supplementary information (ESI) available. See DOI: 10.1039/c9ra05504e
} ion; $, 6,9,16-26$ as is well-known, recently, fluorescent probes based on up-conversion nanoparticles (UCNP), focusing on converting the near-infrared (NIR) light to visible light, have attracted significant attention due to their potential use as bio-probes in detection and imaging., ${ }^{7,10-15}$ Compared to other methods, fluorescent probes based on UCNP present many intriguing advantages due to their unique anti-Stokes fluorescence properties including large penetration depth into tissues, high signal-to-noise ratio, minimum photo-damage to living organisms, high chemical stability and low toxicity. ${ }^{27,28}$ In addition, under NIR excitation, the auto-fluorescence from biological samples and scattering light becomes negligible.

To date, several sensors based on UC-FRET have been developed to detect DNA, metal ions, and small molecules, ${ }^{29,30}$ where the UCNPs (donor) transfer energy to other chromophores (acceptor), resulting in changes in the intensity of UC emission. However, it should be emphasized that the abovementioned UCNP system sensors work in solutions. Liquidbased sensors are usually unstable and irreproducible and have weak up-conversion light (UCL) due to the interaction of UCNPs in solutions, which will unavoidably influence the detection limit and sensitivity. Therefore, it is significant to develop novel solid-state UC sensors with easy operation, stable performance and repeatable responses. For example, Song and co-workers developed solid-state UC biosensors for the detection of copper ions. ${ }^{11}$ However, to the best of our knowledge, $\mathrm{a} \mathrm{Cu}^{2+}$ fluorescent probe based on the solid-state UC-FRET with 
rhodamine $\mathrm{B}$ hydrazide (referred to as $\mathrm{RBH}$ hereinafter) as the energy acceptor has not been reported to date.

In our study, we designed a novel solid-state fluorescent sensor based on the complex of the glass substrate/NaYF ${ }_{4}$ @$\mathrm{NaYF}_{4}: \mathrm{Yb}^{3+}, \mathrm{Er}^{3+}$ film and $\mathrm{RBH}$ for $\mathrm{Cu}^{2+}$ detection on the basis of color change and emission spectra, where the glass substrate/ $\mathrm{NaYF}_{4} @ \mathrm{NaYF}_{4}: \mathrm{Yb}^{3+}, \mathrm{Er}^{3+}$ composite films served as the energy donor and $\mathrm{RBH}$ served as the energy acceptor. Fig. 1 illustrates the preparation process of the $\mathrm{NaYF}_{4} @ \mathrm{NaYF}_{4}: \mathrm{Yb}^{3+}, \mathrm{Er}^{3+}$ coreshell structured probe and the principle of up-conversion FRET in the $\mathrm{RBH}$-modified $\mathrm{NaYF}_{4} @ \mathrm{NaYF}_{4}: \mathrm{Yb}^{3+}, \mathrm{Er}^{3+}$ sensor for $\mathrm{Cu}^{2+}$ detection. The rhodamine framework has been proven to be a classic mode for the construction of fluorescent probes because of its particular spirolactam structure and excellent photophysical properties such as long absorption and emission wavelength, large absorption coefficient and good photostability. ${ }^{31-33}$ When the concentration of $\mathrm{Cu}^{2+}$ is up to a certain amount, the upconversion FRET sensor changes from green to red.

\section{Experimental}

Rare-earth nitrates were purchased from the National Engineering Research Centre of Rare Earth Metallurgy and Function Materials, and other starting materials were bought from the Tianjin GuangFu Technology Development Co., Ltd and Beijing Chemical Plant. All of them were used directly without any further purification. Deionized water was used throughout the experiment.

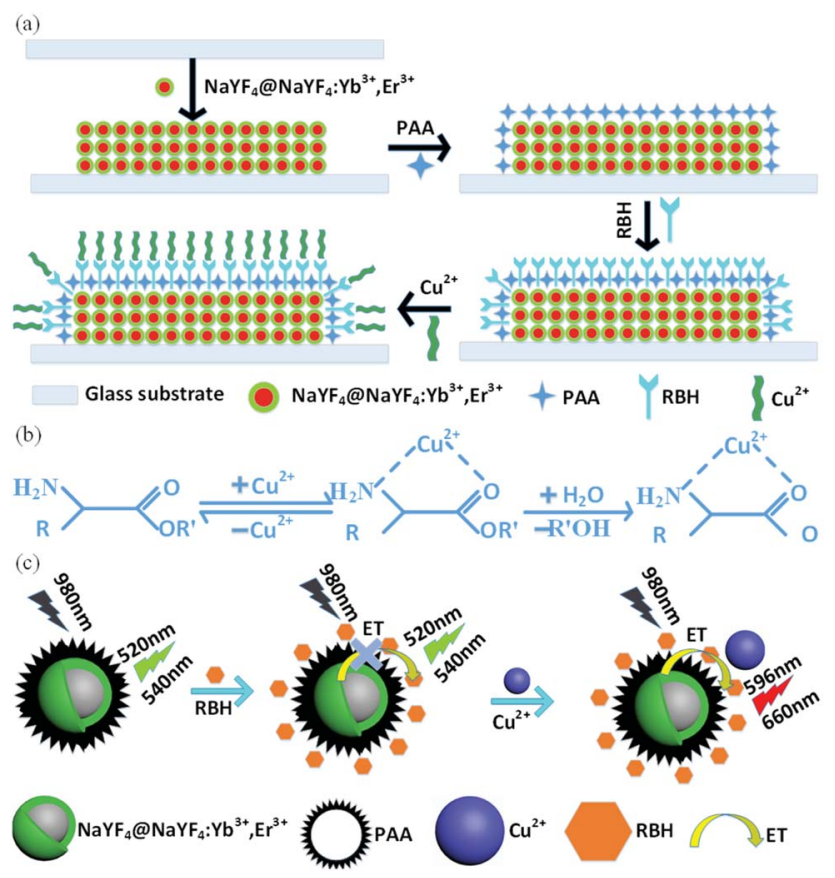

Fig. 1 (a) Schematic of the $\mathrm{NaYF}_{4}\left(\mathrm{aNaYF}_{4}: \mathrm{Yb}^{3+}, \mathrm{Er}^{3+}\right.$ film preparation process. (b) Reaction mechanism of $\mathrm{RBH}$ with $\mathrm{Cu}^{2+}$ ions. (c) Principle of up-conversion for $\mathrm{Cu}^{2+}$ detection using UCNPs as donors and RBH as acceptors in the $\mathrm{NaYF}_{4} \mathrm{QNaYF}_{4}: \mathrm{Yb}^{3+}, \mathrm{Er}^{3+}$ core-shell structured probe.

\subsection{Synthesis of oleic-acid-coated $\mathrm{NaYF}_{4}$}

Oleic-acid-capped $\mathrm{NaYF}_{4}$ was synthesized by a typical solvothermal method ${ }^{34-36}$ with slight modifications. The reaction temperature was controlled in the range of $285-330^{\circ} \mathrm{C}$ to obtain NCNPs with different sizes. The as-prepared products were obtained and washed three times with absolute cyclohexaneethanol $(1: 3 \mathrm{v} / \mathrm{v})$, and the final products were dissolved in the cyclohexane solution for the following experiments.

The synthesis of $\mathrm{NaYF}_{4}$ core nanoparticles was conducted as follows: $\mathrm{YCl}_{3} \cdot 6 \mathrm{H}_{2} \mathrm{O}(1 \mathrm{mmol})$ was mixed with $6 \mathrm{~mL}$ oleic acid (OA) and $15 \mathrm{~mL}$ 1-octadecene (ODE) in a $50 \mathrm{~mL}$ three-necked bottle followed by heating to $160{ }^{\circ} \mathrm{C}$ to form a homogeneous solution; then, the mixture was cooled down to $40{ }^{\circ} \mathrm{C}$. Following this, a $10 \mathrm{~mL}$ methanol solution containing $\mathrm{NaOH}(2.5 \mathrm{mmol})$ and $\mathrm{NH}_{4} \mathrm{~F}$ ( $4 \mathrm{mmol}$ ) was slowly added to the bottle, and the solution quickly became muddy. The mixed solution was stirred for $0.5 \mathrm{~h}$, and it was ensured that all fluoride was consumed completely. Subsequently, the solution was slowly heated to evaporate methanol and then degassed at $120{ }^{\circ} \mathrm{C}$ for $0.5 \mathrm{~h}$ until it was clear. Then, the solution was heated to $300{ }^{\circ} \mathrm{C}$ and maintained at this temperature for $1.5 \mathrm{~h}$ under a nitrogen atmosphere and vigorous stirring. After the solution was naturally cooled down to room temperature, the resulting mixture was centrifugally separated and washed three times with cyclohexane-ethanol $(1: 3 \mathrm{v} / \mathrm{v})$, and the product obtained was the $\mathrm{NaYF}_{4}$ core, which was re-dispersed in cyclohexane.

\subsection{Synthesis of oleic-acid-coated core-shell structured $\mathrm{NaYF}_{4} @ \mathrm{NaYF}_{4}: \mathrm{Yb}^{3+}, \mathrm{Er}^{3+} \mathrm{UCNPs}$}

$\mathrm{NaYF}_{4} @ \mathrm{NaYF}_{4}: \mathrm{Yb}^{3+}, \mathrm{Er}^{3+}$ (core/shell) nanoparticles were synthesized using similar procedures. ${ }^{37,38}$ The $\mathrm{NaYF}_{4} @ \mathrm{NaYF}_{4}: \mathrm{Yb}^{3+}, \mathrm{Er}^{3+}$ shell precursor was first prepared by mixing $\mathrm{YCl}_{3} \cdot 6 \mathrm{H}_{2} \mathrm{O}(0.78 \mathrm{mmol})$, $\mathrm{YbCl}_{3} \cdot 6 \mathrm{H}_{2} \mathrm{O}(0.2 \mathrm{mmol})$ and $\mathrm{ErCl}_{3} \cdot 6 \mathrm{H}_{2} \mathrm{O}(0.02 \mathrm{mmol})$ with $6 \mathrm{~mL} \mathrm{OA}$ and $15 \mathrm{~mL}$ ODE in a $50 \mathrm{~mL}$ flask and subsequently heated at $160{ }^{\circ} \mathrm{C}$ for $0.5 \mathrm{~h}$ to form a homogeneous and clear solution before cooling to $40{ }^{\circ} \mathrm{C}$. The $\mathrm{NaYF}_{4}$ core nanoparticles in cyclohexane $(5 \mathrm{~mL})$ were added to the abovementioned solution, and the mixture was stirred for $0.5 \mathrm{~h}$ followed by heating to $80^{\circ} \mathrm{C}$ to evaporate cyclohexane; after this, the temperature of the mixture was dropped to $40{ }^{\circ} \mathrm{C}$, a $5 \mathrm{~mL}$ methanol solution of $\mathrm{NH}_{4} \mathrm{~F}(4 \mathrm{mmol})$ and $\mathrm{NaOH}(2.5 \mathrm{mmol})$ was injected into the bottle, and the mixed solution was stirred for $0.5 \mathrm{~h}$. Then, the mixed solution was heated to $120^{\circ} \mathrm{C}$ for $0.5 \mathrm{~h}$ to evaporate methanol under $\mathrm{N}_{2}$ until a clear solution was obtained. Subsequently, the resulting mixture was heated to $310{ }^{\circ} \mathrm{C}$ under $\mathrm{N}_{2}$ for $1.5 \mathrm{~h}$, and then, the mixture was allowed to cool down to room temperature. The resulting nanoparticles were precipitated by adding ethanol, obtained by centrifugation at $9000 \mathrm{rpm}$, washed several times with cyclohexane-ethanol, and re-dispersed in cyclohexane. The final products were denoted as OA-UCNPs.

\subsection{Synthesis of water-soluble PAA-modified UCNPs}

Polyacrylic acid (PAA)-modified water-soluble UCNPs were synthesized via a previously reported ligand exchange method ${ }^{37,39}$ with slight modifications. Typically, $0.5 \mathrm{~g}$ PAA was added to $10 \mathrm{~mL}$ diethylene glycol (DEG) in a three-necked flask, and the mixture 
was heated to $110{ }^{\circ} \mathrm{C}$ under vigorous stirring to form a clear solution. A cyclohexane solution containing $100 \mathrm{mg}$ OA-UCNPs was added slowly and refluxed for $2.5 \mathrm{~h}$ at $150{ }^{\circ} \mathrm{C}$ under argon protection. The mixed solution was then heated to $240{ }^{\circ} \mathrm{C}$ for $0.5 \mathrm{~h}$ to get rid of cyclohexane. The resulting solution was cooled down to room temperature, and then, ethanol was added to form a precipitate. The PAA-UCNPs were recovered via centrifugation and washed three times with ethanol/water $(1: 1 \mathrm{v} / \mathrm{v})$.

\subsection{Synthesis of the RBH}

At first, $1.92 \mathrm{~g}$ (4 mmol) rhodamine B was mixed with $30 \mathrm{~mL}$ absolute ethanol in a $100 \mathrm{~mL}$ three-necked bottle, and the mixture was stirred vigorously at room temperature to form a homogeneous purple-red solution; then, $6 \mathrm{~mL}$ hydrazine hydrate $(80 \%)$ was added slowly to the abovementioned solution. After the addition, the stirred mixture was refluxed in an oil bath for $12 \mathrm{~h}$ at $85^{\circ} \mathrm{C}$. The solution changed from purple-red to light-orange and became transparent; it was then cooled down to room temperature. The solvent was removed by rotary evaporation to obtain the residual material, which was then dissolved in $60 \mathrm{~mL}$ of $1 \mathrm{~mol} \mathrm{~L}^{-1}$ hydrochloric acid to develop a wine-red solution; subsequently, $70 \mathrm{~mL}$ of a $1 \mathrm{~mol} \mathrm{~L}^{-1} \mathrm{NaOH}$ solution was added dropwise to the abovementioned solution under constant stirring to obtain a white precipitate. The resulting precipitate was filtered and washed three times with deionized water. After drying the reaction mixture in a vacuum drying oven for $24 \mathrm{~h}$ at room temperature, a light-pink powder was obtained.

\subsection{Characterization and measurements}

The size and morphology of UCNPs were determined by transmission electron microscopy, which was carried out using the Hitachi H-800 transmission electron microscope (TEM) operating at an acceleration voltage of $200 \mathrm{kV}$. The crystalline structure of the samples was characterized by X-ray diffraction (XRD) using a monochromatized $\mathrm{Cu}$ target radiation source $(\lambda=$ $1.54 \AA$ ). ${ }^{1} \mathrm{H}$ Nuclear magnetic resonance (NMR) spectra were obtained using the Bruker Avance III spectrometer.

Ultraviolet-visible (UV-Vis) absorption spectra of the resulting samples were obtained by the UV-1800 UV-visible spectrometer in the range from $200 \mathrm{~nm}$ to $1100 \mathrm{~nm}$. The emission and excitation spectra of RBH were obtained using the SENS9000 spectrometer. The UCL spectra were obtained using the Andor Shamrock SR-750 spectrometer. A photomultiplier (300$850 \mathrm{~nm}$ ) combined with a monochromator and an infrared InGaAs detector (800-2200 $\mathrm{nm}$ ) combined with a double-grating monochromator were used for signal collection from $400 \mathrm{~nm}$ to $2200 \mathrm{~nm}$. A continuous $980 \mathrm{~nm}$ diode laser was used to pump the samples to investigate the steady-state spectra. The luminescence dynamics of the UCNPs were studied using a laser system consisting of a Nd:YAG pumping laser (1064 nm), a third-order harmonic-generator $(355 \mathrm{~nm})$ and a tunable optical parameter oscillator with a pulse duration of $10 \mathrm{~ns}$, a repetition frequency of $10 \mathrm{~Hz}$ and a line width of $4-7 \mathrm{~cm}^{-1}$.

\section{Results and discussion}

\subsection{Structure and morphology of the $\mathrm{NaYF}_{4} @ \mathrm{NaYF}_{4}: \mathrm{Yb}^{3+}, \mathrm{Er}^{3+} \mathrm{UCNPs}$}

The core of the UCNP probe is the host matrix $\left(\mathrm{NaYF}_{4}\right.$ nanoparticle) without doped ions, and the emitter-doped $\mathrm{Ln}^{3+}$ ions are confined in the shell layer. In this structure of UCNPs, most emitting ions were positioned near the surface of the material and close to the external energy acceptors. Fig. 2(a)-(c) show the transmission electron microscopy (TEM) images of the assynthesized nanoparticles, which clearly present the size evolution of the UCNPs. The size of the UCNPs gradually increases, i.e., from the $\mathrm{NaYF}_{4}$ core with an average diameter of $\sim 30 \mathrm{~nm}$ (see Fig. 2(a)) to the $\mathrm{NaYF}_{4} @ \mathrm{NaYF}_{4}: \mathrm{Yb}^{3+}, \mathrm{Er}^{3+}$ core-shell structure with the size of $\sim 38 \mathrm{~nm}$ (see Fig. 2(c)). The X-ray diffraction patterns are shown in Fig. 2(d), which indicate that the obtained nanoparticles are in the hexagonal phase; moreover, these patterns are in good agreement with the standard cards (JCPDS 28-1192), suggesting high product crystallinity.

The hydrophobic UCNPs (with OA as ligands) were first transformed into water-dispersible materials using PAA molecules that replaced the original OA ligands through ligand exchange at the liquid-liquid interface; ${ }^{37,39}$ the successful loading of PAA was confirmed by dissolving the PAA-UCNPs in water to form a homogeneous solution, and their dissolution was the direct experimental evidence of the successful replacement of the OA ligand by the PAA molecules.

\subsection{Photoluminescence spectra of RBH and UCNPs}

Electrostatic interactions between positive and negative charges play a key role in the formation of the FRET probe. The strong attachment of the acceptor on the surface of the UCNP donor can occur by electrostatic interactions during simple mixing. In this study, we have selected an amine-tagged organic dye, $\mathrm{RBH}$,

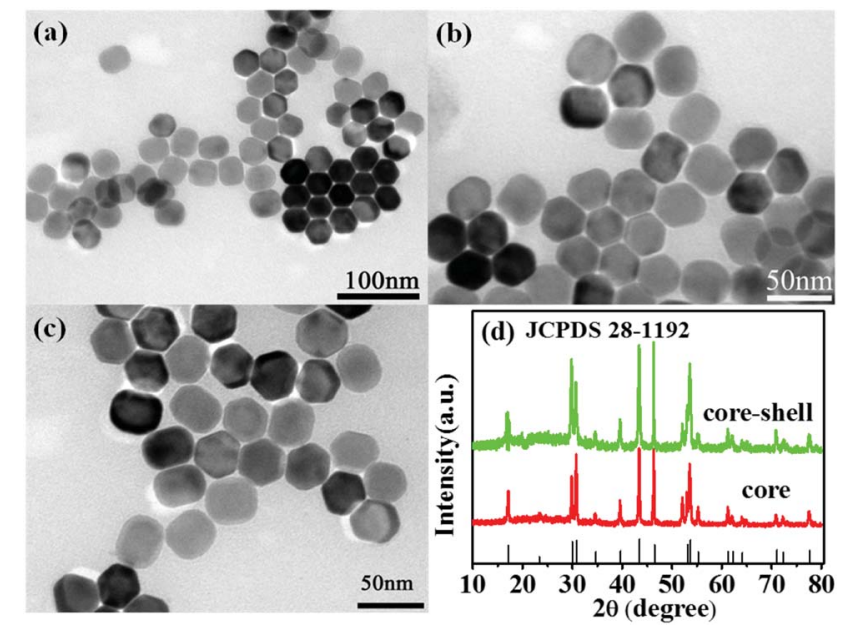

Fig. 2 Transmission electron microscopy (TEM) images of the assynthesized nanoparticles. (a) TEM images of the oleate-capped $\mathrm{NaYF}_{4}$ core, (b) oleate-capped $\mathrm{NaYF}_{4} \mathrm{CNaYF}_{4}: \mathrm{Yb}^{3+}, \mathrm{Er}^{3+}$ core-shell UCNP structure and (c) PAA-modified core-shell UCNP structure. (d) XRD patterns of the obtained core-shell nanocrystals. 
as an energy acceptor, which is positively charged (See Fig. S1 $\dagger$ ) and can be adsorbed on the surface of PAA-modified UCNPs via electrostatic attraction with the negatively charged PAA molecules.

Fig. S2 $\uparrow$ exhibits the ${ }^{1} \mathrm{H}$ NMR spectra of RBH, which indicates that RBH has been synthesized successfully.

The photoluminescence properties of RBH were characterized, as shown in Fig. 3. Fig. 3(a) represents the excitation spectra (left) and emission spectra (right) of RBH in the presence of $\mathrm{Cu}^{2+}$ ions. It can be observed that the excitation bands of RBH range from 460 to $590 \mathrm{~nm}\left(\lambda_{\mathrm{em}}=\right.$ $596 \mathrm{~nm}$ ) and have a peak at $550 \mathrm{~nm}$; moreover, a broad band (570-640 $\mathrm{nm}$ ) with a maximum peak at around $596 \mathrm{~nm}$ is observed, referred to as $\mathrm{RBH}_{596}$ hereinafter $\left(\lambda_{\text {ex }}=\right.$ $540 \mathrm{~nm}$ ). The absorption spectrum of RBH illustrated in Fig. 3(b) (red line) has a broad absorption band, which is consistent with the excitation spectra shown in Fig. 3(a), covering the range of $460-590 \mathrm{~nm}$ that overlaps with the luminescence emission of UCNPs at $520 \mathrm{~nm}$ and $540 \mathrm{~nm}$ (referred to as $\mathrm{Er}_{520-540}$ ). Therefore, the overlapping of the absorption and emission spectra in Fig. 3(b) (black line) ensures a valid non-radiative energy transfer. Moreover, the curves shown in Fig. 3(b) (black line) demonstrate the up-conversion emission spectra of the $\mathrm{NaYF}_{4} @ \mathrm{NaYF}_{4}$ :$\mathrm{Yb}^{3+}, \mathrm{Er}^{3+}$ nanoparticles under $980 \mathrm{~nm}$ excitation, which show three main emission bands in the green and red parts of the visible region; the green emissions are derived from the ${ }^{2} \mathrm{H}_{11 / 2}-{ }^{4} \mathrm{I}_{15 / 2}(520 \mathrm{~nm})$ and ${ }^{4} \mathrm{~S}_{3 / 2}-{ }^{4} \mathrm{I}_{15 / 2}(540 \mathrm{~nm})$ transitions of $\mathrm{Er}^{3+}$, and the red emission is attributed to the ${ }^{4} \mathrm{~F}_{9 /}$ ${ }_{2}{ }^{4} \mathrm{I}_{15 / 2}(660 \mathrm{~nm})$ transition of $\mathrm{Er}^{3+}$. Therefore, the absorption spectrum of RBH overlaps well with the two shortwave emissions $520 \mathrm{~nm}$ and $540 \mathrm{~nm}$ of UCNPs, indicating an efficient energy transfer to the acceptor. Fig. 4 depicts the energy-transfer mechanisms of the $\mathrm{NaYF}_{4} @ \mathrm{NaYF}_{4}$ :$\mathrm{Yb}^{3+}, \mathrm{Er}^{3+}$ UCNPs and the corresponding up-conversion emission spectrum.

To further study the binding properties of $\mathrm{RBH}$ with the $\mathrm{Cu}^{2+}$ ions, we investigated the absorption properties of RBH upon the addition of $\mathrm{Cu}^{2+}$ ions at increasing concentrations $(0-750 \mathrm{nM})$, as shown in Fig. 5 . With the continuous addition of $\mathrm{Cu}^{2+}$ ions, sharp absorption bands centered at $550 \mathrm{~nm}$ and $720 \mathrm{~nm}$ emerged with increasing intensity. It can be observed that the
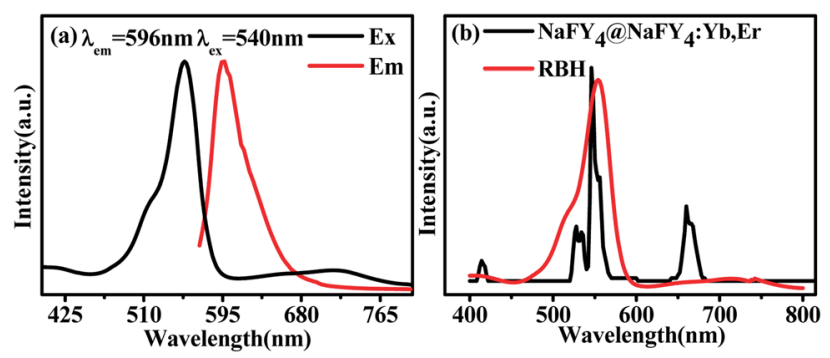

Fig. 3 (a) Normalized excitation $\left(\lambda_{\mathrm{em}}=596 \mathrm{~nm}\right)$ and emission $\left(\lambda_{\mathrm{ex}}=\right.$ $540 \mathrm{~nm}$ ) spectra of RBH in the presence of $\mathrm{Cu}^{2+}$ ions. (b) Normalized fluorescence emission spectrum of UCNPs (black line) and the UV-Vis absorption spectrum of RBH (red line).

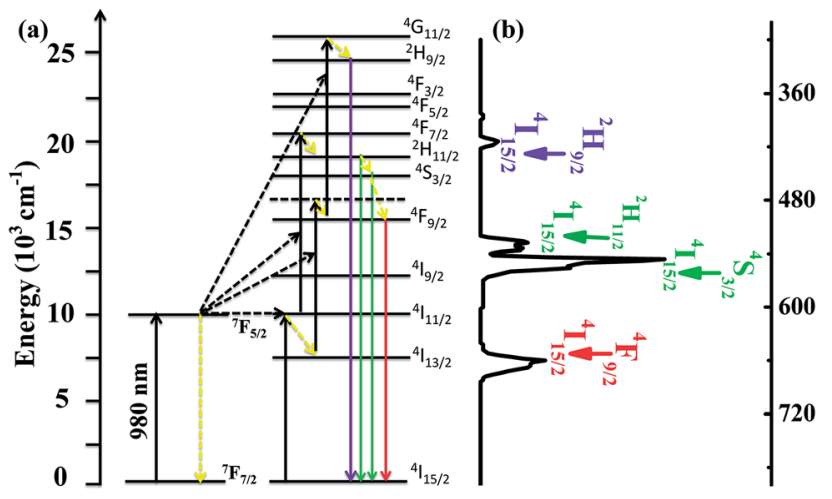

Fig. 4 (a) Proposed energy-transfer mechanisms, showing the UC processes in the $\mathrm{NaYF}_{4}: \mathrm{Yb}^{3+}, \mathrm{Er}^{3+}$ nanoparticles. Key to arrows: solid upward arrows represent excitation process, black dashed lines represent energy transfer, yellow dashed lines represent multiphonon relaxation and solid downward arrows represent emission processes. (b) A typical emission spectrum of as-prepared $\mathrm{NaYF}_{4}: \mathrm{Yb}^{3+}, \mathrm{Er}^{3+}(20 /$ 2 mol\%) under the excitation of a $980 \mathrm{~nm}$ continuous wavelength (CW) diode laser.

line absorption at $550 \mathrm{~nm}$ is dominant and varies significantly; however, the absorption of the red region is weak as compared to the $550 \mathrm{~nm}$ absorption.

\subsection{FRET process from the UCNPs to RBH}

The emission spectra of RBH-UCNPs obtained using different concentrations of $\mathrm{Cu}^{2+}$ ions under $980 \mathrm{~nm}$ excitation are presented in Fig. 6. Fig. 6(a) shows that the intensity of the green up-conversion emission at $520 \mathrm{~nm}$ and $540 \mathrm{~nm}$ decreases with an increase in the $\mathrm{Cu}^{2+}$ concentration. A new emission appears at $596 \mathrm{~nm}$, corresponding to the fluorescence emission from RBH and thus confirming the successful FRET process. Because free RBH with a spirolactam structure is nearly non-fluorescent, in the presence of $\mathrm{Cu}^{2+}$, a delocalized xanthene moiety of the rhodamine B group is generated, resulting in strong fluorescence emission, ${ }^{41,42}$ as shown in Fig. 1(b) and (c). Among the more relevant transition metal ions, the $\mathrm{Cu}^{2+}$ ion has a particularly high thermodynamic affinity for typical N,O-chelate ligands and fast metal-to-ligand binding kinetics, which is

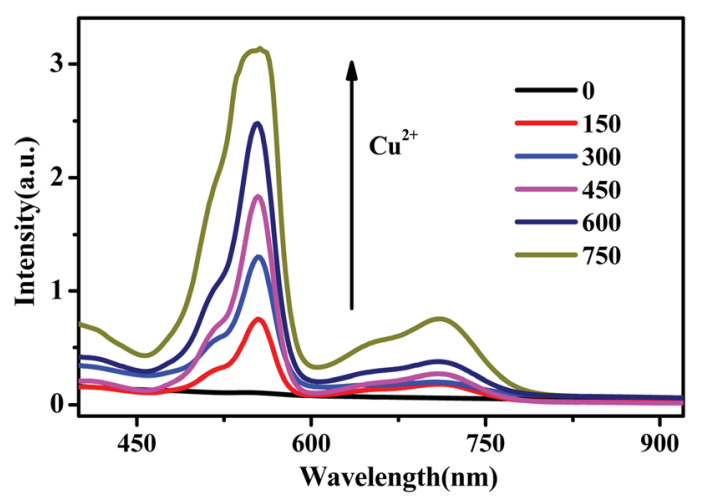

Fig. 5 UV-Vis absorption spectra of RBH in the presence of $\mathrm{Cu}^{2+}$ ions at different concentrations. 


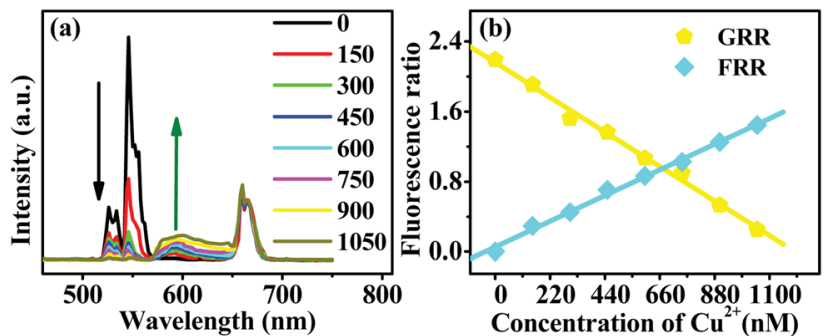

Fig. 6 (a) Fluorescence spectra of $\mathrm{NaYF}_{4} \mathrm{ONaYF}_{4}: \mathrm{Yb}^{3+}, \mathrm{Er}^{3+}$ with $\mathrm{RBH}$ in the presence of increasing concentrations of $\mathrm{Cu}^{2+}(0-1050 \mathrm{nM})$ upon $980 \mathrm{~nm}$ excitation. (b) Variation in both green-to-red emission ratio (GRR) of $\mathrm{Er}^{3+}$ and $\mathrm{RBH}$ fluorescence emission-to-red emission ratio (FRR) at different concentrations of $\mathrm{Cu}^{2+}$ ions.

responsible for the high selectivity of the sensor towards $\mathrm{Cu}^{2+}$ ions. ${ }^{40,43}$

With an increase in the concentrations of $\mathrm{Cu}^{2+}$ ions, the fluorescence intensity of $\mathrm{RBH}$ increases gradually, whereas the intensity of the up-conversion emission at $520 \mathrm{~nm}$ and $540 \mathrm{~nm}$ decreases dramatically, as shown in Fig. 6, and the red emission of the UCNPs at $660 \mathrm{~nm}$ remains nearly unchanged. Since RBH has no absorption for the red light of UCNPs at $660 \mathrm{~nm}$, the red emission intensity can thus be used as a reference. When the $\mathrm{Cu}^{2+}$ ion concentration is up to a significant amount (600 nM), the green emissions at $520 \mathrm{~nm}$ and $540 \mathrm{~nm}$ are nearly absent. Moreover, the red emission becomes dominant among the entire emission lines.

Fig. 6(b) exhibits the variation in both the green $\left({ }^{2} \mathrm{H}_{11 / 2}-{ }^{4} \mathrm{I}_{15 / 2}\right.$ and ${ }^{4} \mathrm{~S}_{3 / 2}-{ }^{4} \mathrm{I}_{15 / 2}$ )-to-red $\left({ }^{4} \mathrm{~F}_{9 / 2}-{ }^{4} \mathrm{I}_{15 / 2}\right)$ emission ratio (GRR) of $\mathrm{Er}^{3+}$ and $\mathrm{RBH}$ emission-to-red $\left({ }^{4} \mathrm{~F}_{9 / 2}-{ }^{4} \mathrm{I}_{15 / 2}\right)$ emission ratio (FRR) at different concentrations of $\mathrm{Cu}^{2+}$ ions. The variation trend of the green-to-red emission ratio supports the UCNP emission/RBH absorption mechanism hypothesis. The changes in the fluorescence emissionto-red emission ratio also suggest the presence of resonant energy transfer; this indicates successful energy transfer between the UCNP donor and the $\mathrm{RBH}$ acceptor. ${ }^{9}$ Compared to the case reported in ref. 9, herein, when the concentration of the $\mathrm{Cu}^{2+}$ ion was up to $600 \mathrm{nM}$, the ratio of GRR was less than 1; these results indicated that the UC nano-probe visibly changed from green to red, similar to the case of $\mathrm{pH}$ indicator strips, and the solid sensor based on the color change for $\mathrm{Cu}^{2+}$ detection was realizable.

The corresponding images of the RBH-UCNP FRET probe in the absence and presence of $\mathrm{Cu}^{2+}$ are shown in Fig. S3. $\dagger$ It can be observed that in the absence of $\mathrm{Cu}^{2+}$ ions, the RBH-UCNP probe presents green emissions of $\mathrm{Er}^{3+}$ under $980 \mathrm{~nm}$ excitation. As the $\mathrm{Cu}^{2+}$ concentration increases, the intensity of the green up-conversion emissions gradually decreases until they are nearly absent. The red emission becomes dominant, and the RBH-UCNP probe presents a red color.

To further confirm the FRET process from the UCNP donors to the $\mathrm{RBH}$ acceptors, the luminescence decay dynamics for the ${ }^{4} \mathrm{~S}_{3 / 2}-{ }^{4} \mathrm{I}_{15 / 2}$ transition of $\mathrm{Er}^{3+}$ with and without $\mathrm{Cu}^{2+}$ ions were measured and compared, as shown in Fig. S4. $\dagger$ It can be observed that under $980 \mathrm{~nm}$ excitation, the decay time of $\mathrm{Er}^{3+}$ with the $\mathrm{Cu}^{2+}$ ions is shorter than that without $\mathrm{Cu}^{2+}$ ions. The $\mathrm{Er}^{3+}$ lifetime decreases from $519 \mu$ s to
$314 \mu \mathrm{s}$, which is an evidence for the FRET from $\mathrm{Er}^{3+}$ to RBH. ${ }^{9,12}$

\subsection{Fluorescence response characteristics of the probe for $\mathrm{Cu}^{2+}$ detection}

An important feature of the probe is its high selectivity towards the $\mathrm{Cu}^{2+}$ ions over other competitive species such as $\mathrm{Ag}^{2+}, \mathrm{Na}^{+}$, $\mathrm{Fe}^{3+}, \mathrm{Ba}^{2+}, \mathrm{Pb}^{2+}, \mathrm{Gd}^{3+}, \mathrm{Ca}^{2+}, \mathrm{Ni}^{2+}, \mathrm{Co}^{2+}, \mathrm{Mn}^{2+}, \mathrm{K}^{+}$, and $\mathrm{Zn}^{2+}$. No obvious responses were observed in the absorption spectra of $\mathrm{RBH}$ upon the addition of the abovementioned species, as shown in Fig. 7(a). However, the addition of equivalent amount of $\mathrm{Cu}^{2+}$ ion induced a large absorption band centered at $540 \mathrm{~nm}$ accompanied by the remarkable change of the probe from colorless to magenta, as displayed in Fig. 7(b). This is because $\mathrm{RBH}$ possesses suitable affinity towards $\mathrm{Cu}^{2+}$ ions over other biologically relevant metal ions. The $\mathrm{Cu}^{2+}$ ion can promote the hydrolysis of the $\alpha$-amino acid esters of $\mathrm{RBH}$ and yield the $\mathrm{Cu} \cdot \boldsymbol{\alpha}$ amino acid chelate; thus, the ring-opening of RBH occurs. The color of the solution to which $\mathrm{Cu}^{2+}$ was added changed significantly. ${ }^{39}$ Note that the addition of the $\mathrm{Fe}^{3+}$ ions caused a slight change in the color of the solution. This might be due to the strong oxidizing property of the $\mathrm{Fe}^{3+}$ ions, which oxidized phenylhydrazine. The spirocyclic structure of $\mathrm{RBH}$ was destroyed, and the solution turned from colorless to light red.

To further estimate the selectivity of the solid-based FRET probe for copper detection, the integrated intensities of $\mathrm{Ag}^{2+}$, $\mathrm{Na}^{+}, \mathrm{Fe}^{3+}, \mathrm{Ba}^{2+}, \mathrm{Pb}^{2+}, \mathrm{Gd}^{3+}, \mathrm{Ca}^{2+}, \mathrm{Ni}^{2+}, \mathrm{Co}^{2+}, \mathrm{Mn}^{2+}, \mathrm{K}^{+}$, and $\mathrm{Zn}^{2+}$ were investigated in the presence of $\mathrm{Cu}^{2+}$ ions. As shown in Fig. 8, only $\mathrm{Cu}^{2+}$ ions led to a dramatic change in the fluorescence intensity, showing an obvious difference from the cases of other metal ions. There was no significant fluorescence intensity variation in the presence of other ions except for $\mathrm{Cu}^{2+}$ ions; this indicated the high selectivity of the proposed probe for the $\mathrm{Cu}^{2+}$ ions.
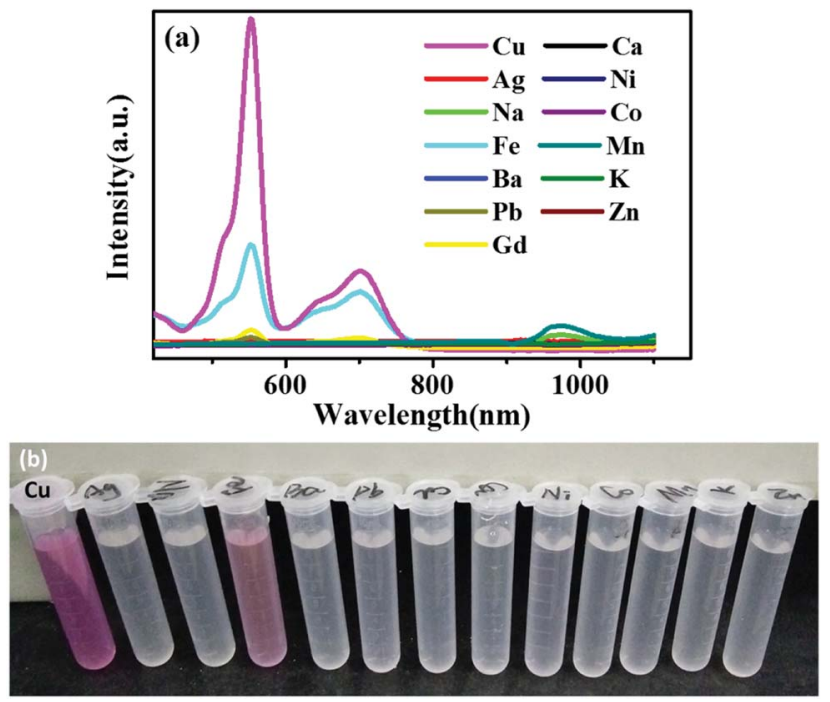

Fig. 7 (a) UV-Vis absorption spectra of $\mathrm{RBH}$ upon the addition of various metal ions (10 nM, in absolute ethyl alcohol) and (b) naked-eye detectable color changes. 


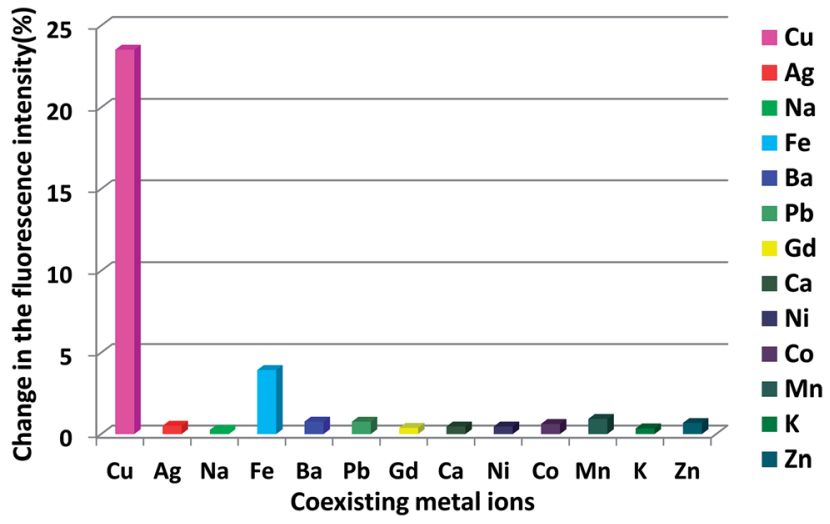

Fig. 8 Detection selectivity of the proposed UCNP probe for $\mathrm{Cu}^{2+}$ ions against other metal ions.

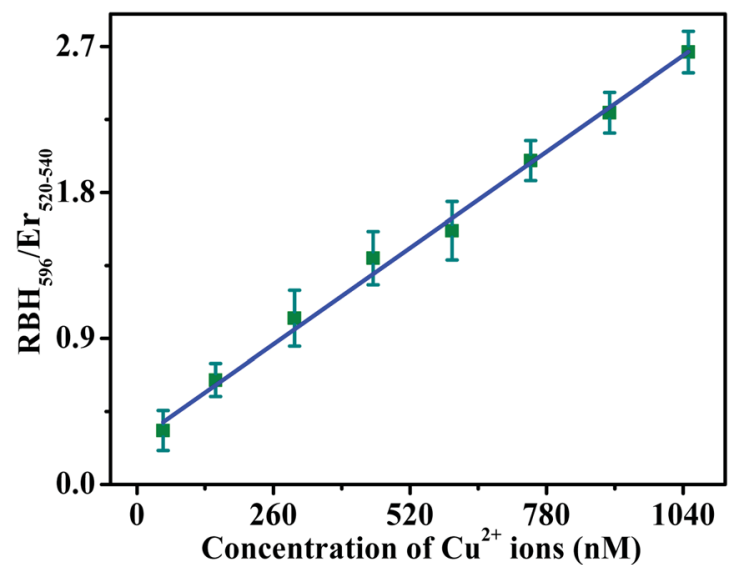

Fig. 9 Calibration curve of the integrated luminescence intensity ratio $\mathrm{RBH}_{596} / \mathrm{Er}_{520-540}$ versus the concentration of $\mathrm{Cu}^{2+}$ ions under $980 \mathrm{~nm}$ excitation for the FRET detection of $\mathrm{Cu}^{2+}$ ions.

The UCNPs utilize NIR excitation rather than ultraviolet (UV) excitation, thereby significantly minimizing background autofluorescence, photobleaching, and photodamage to biological specimens. ${ }^{27}$ To study the anti-interference of the proposed UCNPbased sensor, the fluorescence characteristics with and without the serum were studied, as shown in Fig. S5. $\dagger$ It can be observed that the fluorescence intensity presents an insignificant change, which indicates that the serum does not significantly influence the $\mathrm{Cu}^{2+}$ detection. The abovementioned results suggest that the proposed UCNP-based sensor exhibits a good anti-interference performance.

Fig. 9 shows the curve of $\mathrm{RBH}_{596} / \mathrm{Er}_{520-540}$ as a function of the amount of $\mathrm{Cu}^{2+}$ ions. The signal of $\mathrm{RBH}_{596} / \mathrm{Er}_{520-540}$ increases steadily with an increase in the $\mathrm{Cu}^{2+}$ concentration. There is a good linear relationship between the fluorescence intensity ratio and the concentration of $\mathrm{Cu}^{2+}$ ions. $R$, defined as the correlation coefficient of the linear fit, is 0.9925 in the range of $50-1050 \mathrm{nM}$.

\section{Conclusions}

In summary, we presented a new FRET-based NIR solid statebased up-conversion nano-probe for copper ion detection, which overcame the lack of NIR-excitable probes for $\mathrm{Cu}^{2+}$ ions. The proposed sensor has the advantages of a quick response towards $\mathrm{Cu}^{2+}$ ions, weak auto-fluorescence background, good selectivity, and ease of fabrication. Note that the solid-based UC sensor is more stable, convenient and applicable than the liquid-based UC sensor; thus, this system have further potential applications in $\mathrm{Cu}^{2+}$ detection in the sensor fields. Furthermore, we established a solid-based sensor with a promising prospect, which was used to detect the $\mathrm{Cu}^{2+}$ ions via color change and emission spectra. Thus, it is expected that the upconversion solid-based sensor with the color change property may have potential applications in $\mathrm{Cu}^{2+}$ detection.

\section{Conflicts of interest}

There are no conflicts to declare.

\section{Acknowledgements}

This study was supported by the Opening Foundation of Engineering Research Center of New Energy Technology of Jiangxi Province (no. JXNE2018-05), National Natural Science Foundation of China (no. 11875012), Young Scientists Fund of the National Natural Science Foundation of China (Grant no. 61204071), and Doctoral Research Start-Up Fund. We thank Prof. Hongwei Song and associate Prof. Wen $\mathrm{Xu}$ in Jilin University for offering us access to the fluorescence dynamic measurement using the Nd:YAG pumping laser and for helpful discussions.

\section{References}

1 Y. Yang, Q. Zhao, W. Feng and F. Li, Luminescent upconversion for bioimaging, Chem. Rev., 2012, 113, 192270.

2 Z. Hu, J. Hu, Y. Cui, G. Wang, X. Zhang, K. Uvdal and H. Gao, A facile "click" reaction to fabricate a FRET-based ratiometric fluorescent $\mathrm{Cu}^{2+}$ probe, J. Mater. Chem. B, 2014, 2, 4467-4472.

3 L. Gao, L. Li, X. Wang, P. Wu, Y. Cao, B. Liang, X. Li, Y. Lin, Y. Lu and X. Guo, Graphene-DNAzyme junctions: a platform for direct metal ion detection with ultrahigh sensitivity, Chem. Sci., 2015, 6, 2469-2473.

4 P. Verwilst, K. Sunwoo and J. S. Kim, The role of copper ions in pathophysiology and fluorescent sensors for the detection thereof, Chem. Commun., 2015, 51, 5556-5571.

5 S. Hu, J. Song, F. Zhao, X. Meng and G. Wu, Highly sensitive and selective colorimetric naked-eye detection of $\mathrm{Cu}^{2+}$ in aqueous medium using a hydrazine chemosensor, Sens. Actuators, B, 2015, 215, 241-248.

6 C. Li, J. Liu, S. Alonso, F. Li and Y. Zhang, Upconversion nanoparticles for sensitive and in-depth detection of $\mathrm{Cu}^{2+}$ ions, Nanoscale, 2012, 4, 6065-6071.

7 J. Peng, W. Xu, C. L. Teoh, S. Han, B. Kim, A. Samanta, J. C. Er, L. Wang, L. Yuan, X. Liu and Y.-T. Chang, Highefficiency in vitro and in vivo detection of $\mathrm{Zn}^{2+}$ by dye- 
assembled upconversion nanoparticles, J. Am. Chem. Soc., 2015, 137, 2336-2342.

8 Z. Li, S. Lv, Y. Wang, S. Chen and Z. Liu, Construction of LRET-based nanoprobe using upconversion nanoparticles with confined emitters and bared surface as luminophore, J. Am. Chem. Soc., 2015, 137, 3421-3427.

9 J. Zhang, B. Li, L. M. Zhang and H. Jiang, An optical sensor for $\mathrm{Cu}(\mathrm{II})$ detection with upconverting luminescent nanoparticles as an excitation source, Chem. Commun., 2012, 48, 4860-4862.

10 F. Chen, W. Bu, S. Zhang, J. Liu, W. Fan, L. Zhou, W. Peng and J. Shi, $\mathrm{Gd}^{3+}$-ion-doped upconversion nanoprobes: relaxivity mechanism probing and sensitivity optimization, Adv. Funct. Mater., 2013, 23, 298-307.

11 S. Xu, W. Xu, Y. Wang, S. Zhang, Y. Zhu, L. Tao, L. Xia, P. Zhou and H. Song, $\mathrm{NaYF}_{4}: \mathrm{Yb}, \mathrm{Tm}$ nanocrystals and $\mathrm{TiO}_{2}$ inverse opal composite films: a novel device for upconversion enhancement and solid-based sensing of avidin, Nanoscale, 2014, 6, 5859-5870.

12 S. Xu, S. Xu, Y. Zhu, W. Xu, P. Zhou, C. Zhou, B. Dong and H. Song, A novel upconversion, fluorescence resonance energy transfer biosensor (FRET) for sensitive detection of lead ions in human serum, Nanoscale, 2014, 6, 12573-12579.

13 X. Li, Y. Wu, Y. Liu, X. Zou, L. Yao, F. Li and W. Feng, Cyclometallated ruthenium complex-modified up-conversion nanophosphors for selective detection of $\mathrm{Hg}^{2+}$ ions in water, Nanoscale, 2014, 6, 1020-1028.

14 F. Wang, D. Banerjee, Y. Liu, X. Chen and X. Liu, Upconversion nanoparticles in biological labeling, imaging, and therapy, Analyst, 2010, 135, 1839-1854.

15 Q. Liu, J. Peng, L. Sun and F. Li, High-efficiency upconversion luminescent sensing and bioimaging of $\mathrm{Hg}$ (II) by chromophoric ruthenium complex-assembled nanophosphors, ACS Nano, 2011, 5, 8040-8048.

16 A. Salinas-Castillo, M. Ariza-Avidad, C. Pritz, M. CamprubíRobles, B. Fernández, M. J. Ruedas-Rama, A. MegiaFernández, A. Lapresta-Fernández, F. Santoyo-Gonzalez and A. Schrott-Fischer, Carbon dots for copper detection with down and upconversion fluorescent properties as excitation sources, Chem. Commun., 2013, 49, 1103-1105.

17 A. P. de Silva, H. Q. N. Gunaratne, T. Gunnlaugsson, A. J. M. Huxley, C. P. McCoy, J. T. Rademacher and T. E. Rice, Signaling recognition events with fluorescent sensors and switches, Chem. Rev., 1997, 97, 1515-1566.

18 S. Na, Z. Ying, C. Sinman, Y. Ronghua, C. Winghong, M. Tain and L. K. L. Feng, Copper ion-selective fluorescent sensor based on the inner filter effect using a spiropyran derivative, Anal. Chem., 2005, 77, 7294-7303.

19 F. Wang, Z. Gu, L. Wu, W. Wang, X. Xia and Q. Hao, Graphene quantum dots as a fluorescent sensing platform for highly efficient detection of copper(II) ions, Sens. Actuators, B, 2014, 190, 516-522.

$20 \mathrm{~J}$. Wu, W. Liu, J. Ge, H. Zhang and P. Wang, New sensing mechanisms for design of fluorescent chemosensors emerging in recent years, Chem. Soc. Rev., 2011, 40, 34833495.
21 M. Taki, S. Iyoshi, A. Ojida, I. Hamachi and Y. Yamamoto, Development of highly sensitive fluorescent probes for detection of intracellular copper(I) in living systems, J. Am. Chem. Soc., 2010, 132, 5938-5939.

22 Z. Guo, W. Chen and X. Duan, Highly selective visual detection of $\mathrm{Cu}$ (II) utilizing intramolecular hydrogen bond-stabilized merocyanine in aqueous buffer solution, Org. Lett., 2010, 12, 2202-2205.

23 Y. Liu, Y. Zhao and Y. Zhang, One-step green synthesized fluorescent carbon nanodots from bamboo leaves for copper (II) copper(II) ion detection, Sens. Actuators, B, 2014, 196, 647-652.

24 H. S. Jung, P. S. Kwon, J. W. Lee, J. I. Kim, C. S. Hong, J. W. Kim, S. Yan, J. Y. Lee, J. H. Lee, T. Joo and J. S. Kim, Coumarin-derived $\mathrm{Cu}^{2+}$-selective fluorescence sensor: synthesis, mechanisms, and applications in living cells, J. Am. Chem. Soc., 2009, 131, 20082012.

25 C. Zong, K. Ai, G. Zhang, H. Li and L. Lu, Dual-emission fluorescent silica nanoparticle-based probe for ultrasensitive detection of $\mathrm{Cu}^{2+}$, Anal. Chem., 2011, 83, 3126-3132.

26 Y. Su, B. Shi, S. Liao, Y. Qin, L. Zhang, M. Huang and S. Zhao, Facile preparation of fluorescent polydihydroxyphenylalanine nanoparticles for label-free detection of copper ions, Sens. Actuators, B, 2016, 225, 334-339.

27 F. Wang and X. Liu, Recent advances in the chemistry of lanthanide-doped upconversion nanocrystals, Chem. Soc. Rev., 2009, 38, 976-989.

28 C. Wang, L. Chen and Z. Liu, Drug delivery with upconversion nanoparticles for multi-functional targeted cancer cell imaging and therapy, Biomaterials, 2011, 32, 1110-1120.

29 R. Deng, X. Xie, M. Vendrell, Y. Chang and X. Liu, Intracellular glutathione detection using $\mathrm{MnO}_{2}$-nanosheetmodified upconversion nanoparticles, J. Am. Chem. Soc., 2011, 133, 20168-20171.

30 Y. Liu, M. Chen, T. Cao, Y. Sun, C. Li, Q. Liu, T. Yang, L. Yao, W. Feng and F. Li, A cyanine-modified nanosystem for in vivo up-conversion luminescence bioimaging of methylmercury, $J$. Am. Chem. Soc., 2013, 135, 9869-9876.

31 A. K. Mahapatra, S. K. Manna, D. Mandal and C. D. Mukhopadhyay, Highly sensitive and selective rhodamine-based "Off-On" reversible chemosensor for Tin $\left(\mathrm{Sn}^{4+}\right)$ and imaging in living cells, Inorg. Chem., 2013, 52, 10825-10834.

32 S. Mandal, A. Banerjee, D. Ghosh, D. K. Mandal, D. A. Safin, M. G. Babashkina, K. Robeyns, M. P. Mitoraj, P. Kubisiak and Y. Garcia, An anion induced multi signaling probe for $\mathrm{Hg}^{2+}$ and its application for fish kidney and liver tissue imaging studies, Dalton Trans., 2015, 44, 13186-13195.

33 M. Li, X. Jiang, H. Wu, H. Lu, H. Li, H. Xu, S. Zang and T. C. Mak, A dual functional probe for "turn-on" fluorescence response of $\mathrm{Pb}^{2+}$ and colorimetric detection of $\mathrm{Cu}^{2+}$ based on a rhodamine derivative in aqueous media, Dalton Trans., 2015, 44, 17326-17334.

$34 \mathrm{Z}$. Li and Y. Zhang, An efficient and user-friendly method for the synthesis of hexagonal-phase $\mathrm{NaYF}_{4}: \mathrm{Yb}, \mathrm{Er} / \mathrm{Tm}$ 
nanocrystals with controllable shape and upconversion fluorescence, Nanotechnology, 2008, 19, 345606.

35 Y. Dai, H. Xiao, J. Liu, Q. Yuan, P. A. Ma, D. Yang, C. Li, Z. Cheng, Z. Hou and P. Yang, In vivo multimodality imaging and cancer therapy by near-infrared light-triggered trans-platinum pro-drugconjugated upconverison nanoparticles, J. Am. Chem. Soc., 2013, 135, 18920-18929.

36 B. Chen, B. Dong, J. Wang, S. Zhang, L. Xu, W. Yu and H. Song, Amphiphilic silane modified $\mathrm{NaYF}_{4}: \mathrm{Yb}, \mathrm{Er}$ loaded with $\mathrm{Eu}(\mathrm{TTA})_{3}(\mathrm{TPPO})_{2}$ nanoparticles and their multi-functions: dual mode temperature sensing and cell imaging, Nanoscale, 2013, 5, 8541-8549.

37 C. Liu, H. Wang, X. Li and D. Chen, Monodisperse, size- tunable and highly efficient $\beta-\mathrm{NaYF}_{4}: \mathrm{Yb}, \quad \mathrm{Er}(\mathrm{Tm})$ up-conversion luminescent nanospheres: controllable synthesis and their surface modifications, J. Mater. Chem., 2009, 19, 3546-3553.

38 F. Wang, J. Wang and X. Liu, Direct evidence of a surface quenching effect on size-dependent luminescence of upconversion nanoparticles, Angew. Chem., Int. Ed., 2010, 49, 7456-7460.

39 L. Xiong, T. Yang, Y. Yang, C. Xu and F. Li, Long-term in vivo biodistribution imaging and toxicity of polyacrylic acidcoated upconversion nanophosphors, Biomaterials, 2010, 31, 7078-7085.

40 V. Dujols, F. Ford and A. W. Czarnik, A long-wavelength fluorescent chemodosimeter selective for $\mathrm{Cu}$ (II) ion in water, J. Am. Chem. Soc., 1997, 119, 7386-7387.

41 Y. Qian, L. Cao, C. Jia, P. O. Boamah, Q. Yang, C. Liu, Y. Huang and Q. Zhang, A highly selective chemosensor for naked-eye sensing of nanomolar $\mathrm{Cu}(\mathrm{II})$ in an aqueous medium, RSC Adv., 2015, 5, 77965-77972.

42 T. Nguyen and M. B. Francis, Practical synthetic route to functionalized rhodamine dyes, Org. Lett., 2003, 5, 32453248.

43 R. Krämer, Fluorescent chemosensors for $\mathrm{Cu}^{2+}$ ions: fast, selective, and highly sensitive, Angew. Chem., Int. Ed., 1998, 37, 772-773. 